\title{
Real-time monitoring of a cobalt-mediated one-pot transition metal- catalyzed multicomponent reaction
}

\author{
Antônio E. M. Crotti ${ }^{1,2^{*}}$, Daniel Previdi, ${ }^{2}$ Paulo M. Donate, ${ }^{2}$ and J. Scott McIndoe ${ }^{2, *}$
}

${ }^{1}$ Department of Chemistry, University of Victoria, P. O. Box 3065, Victoria, BC V8W 3V6, Canada

${ }^{2}$ Departamento de Química, Faculdade de Filosofia, Ciências e Letras de Ribeirão Preto, Universidade de São Paulo, CEP 14040-901 Ribeirão Preto, SP, Brazil

\section{ORCID}

Antônio E. M. Crotti: https://orcid.org/0000-0002-1730-1729

Daniel Previdi: https://orcid.org/0000-0002-3509-8541

Paulo M. Donate: https://orcid.org/0000-0002-1404-5328

J. Scott McIndoe: https://orcid.org/0000-0001-7073-5246

\section{Correspondence}

J. Scott McIndoe, Department of Chemistry, University of Victoria, P. O. Box 3065, Victoria, BC V8W 3V6, Canada. E-mail: mcindoe@uvic.ca

Antônio E. M. Crotti, ${ }_{-}^{2}$ Departamento de Química, Faculdade de Filosofia, Ciências e Letras de Ribeirão Preto, Universidade de São Paulo, Av. Bandeirantes, 3900, Monte Alegre, CEP 14040-901 Ribeirão Preto, SP, Brazil. Email: millercrotti@,ffclrp.usp.br 


\begin{abstract}
In this paper, pressurized sample infusion electrospray ionization mass spectrometry (PSI-ESIMS) and FTIR spectroscopy was used to investigate the mechanism of a like-Barbier cobalt-mediated onepot transition metal-catalyzed multicomponent reaction (MCR). The use of charge-tagged aryl halides allowed for the detection of cobalt(II)-promoted hydrodehalogenation products. Although these products were also detected in the off-line ESI-MS monitoring, the ability of PSI-ESI-MS to track real-time changes in the reaction mixture composition proved cobalt(II) was responsible for the undesired transformation. The occurrence of cobalt(II)-promoted hydrodehalogenation as a side reaction in this MCR had not been considered in previous mechanistic proposals and represents an important mechanistic consideration.
\end{abstract}

\title{
Keywords:
}

charge tagged aryl halides; hydrodehalogenation; multicomponent reaction 


\section{Introduction}

Mass spectrometry (MS) has emerged as an additional tool to spectroscopic (e.g. NMR, IR and $\mathrm{UV} /$ vis) and electrochemical techniques for the investigation of reaction mechanisms [1, 2]. The development of atmospheric pressure ionization (API) techniques, especially electrospray ionization (ESI), has enabled MS to detect transient species directly from the reaction vessel, which has furnished valuable information enabling elucidation and consolidation of the mechanisms proposed for reactions such as the Mannich-type $\alpha$-methylenation [3], Stille reaction [2], Ugi reaction [4], Heck reaction [5, 6], Suzuki reaction [6], Sonogashira reaction [7], Morita-Baylis-Hillman reaction [8, 9], Petasis olefination [10], Ziegler-Natta polymerization [11], Pauson-Khand reaction [12] and hydrodehalogenation [13], among others.

Electrospray ionization mass spectrometry (ESI-MS) and electrospray ionization tandem mass spectrometry (ESI-MS/MS) monitoring of reaction solutions can be conducted by off-line sampling methods [14] or by continuous on-line monitoring such as with pressurized sample infusion (PSI) $[15,16]$. In PSI-ESI-MS, one of the ends of a PEEK tube is inserted into the reaction mixture through a rubber septum, whereas the other end is connected to the ESI source inlet. Continuous sample introduction into the mass spectrometer occurs thanks to a slight overpressure of an inert gas (between one and five psi) applied to the reaction vessel. PSI has been successfully employed for real-time analysis of several catalytic reactions (e.g., palladium and rhodium in alkyne hydrogenation [17] and hydrodehalogenation of aryl iodides [13]).

The approach of using charge-tagged compounds in PSI-ESI-MS allows monitoring not only reaction intermediates but also changes in their relative abundances over the course of the reaction [18]. However, homogeneity of the solution has been reported to play a key role in PSI experiments, as phase separation or insolubility result in irregularities in the spray, making the traces very noisy [19]. For these reasons, the use of PSI-ESI-MS to investigate reaction mechanisms has been largely limited to homogeneous catalytic systems.

Multicomponent reactions (MCRs) are defined as reactions in which three or more reactants are added into only one reaction vessel (one-pot reaction), to yield product molecules containing the essential 
parts of the reactant structures. These reactions eliminate the need to isolate and purify the intermediate products, which saves reactants, solvent, time, and energy [20, 21]. Because MCRs allow the structural blocks of all the reactants to connect in a single pot, these reactions have become an attractive alternative to classic multi-step synthesis [22]. Moreover, by combining reactants with minimal structural differences, a single MCR can result in a library of compounds [21]. ESI-MS/MS has been successfully used to characterize the intermediates of several MCRs, such as the Mannich reaction [23], the Hantzsch reaction [23, 24], the Ugi reaction [4], the Petasis Borono-Mannich reaction [25], the Biginelli reaction [21, 26, 27$]$ and the Pauson-Khand reaction [12].

In this paper, the potential of PSI-ESI-MS to investigate MCR mechanisms of heterogeneous catalytic systems was explored. For this purpose, we have chosen as a model the like-Barbier cobaltmediated one-pot transition metal-catalyzed MCR (Scheme 1), which was first reported by Le Floch and co-workers for the synthesis of 2,3-di- and 2,2,3-trisubstituted-3-methoxycarbonyl- $\gamma$-lactones and related compounds [28].
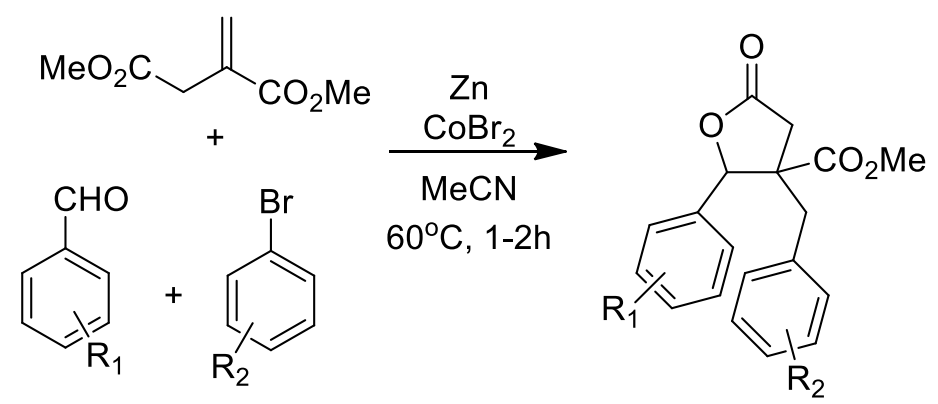

Scheme 1. Mediated-cobalt synthesis of 2,3-di- and 2,2,3-trisubstituted-3-methoxycarbonyl$\gamma$-lactones[28].

\section{Experimental section}

\section{$2.1 \quad$ Chemicals}

Solvents and chemicals were purchased from Sigma-Aldrich. THF was HPLC grade, previously purified on a Grubbs-type (MBraun SPS-800) solvent purification system. Acetone was purified by distillation from 
potassium carbonate [29]. Acetonitrile was HPLC grade, purified by distillation from calcium hydride [29]. Triethylamine was purified by distillation from calcium hydride [29]. Deionized water was obtained from a Millipore Milli-DI water purification system.

\subsection{Nuclear magnetic resonance (NMR)}

The ${ }^{1} \mathrm{H}$ and ${ }^{13} \mathrm{C}$ NMR spectra were recorded on a Bruker Avance $300 \mathrm{MHz}$ spectrometer as solutions prepared in DMSO- $d_{6}$ or $\mathrm{CDCl}_{3}$. NMR data were processed using Bruker TopSpin 3.6.0 software.

\subsection{Synthesis of charge-tagged compounds 1 and 2 and $\gamma$-lactone 3}

Compound 1 (4-bromo-N,N,N-triethyl-benzenemethanaminium hexafluorophosphate) was synthesized according to the methodology proposed by Roiser and co-workers [30] with some modifications (Scheme 2). To a 250-mL screw-capped round-bottom flask, p-bromobenzyl bromide (3.060 g, $12.2 \mathrm{mmol})$, THF $(100 \mathrm{~mL})$, and triethylamine $(4.5 \mathrm{~mL}, 3.267 \mathrm{~g}, 32.3 \mathrm{mmol})$ were added. The resulting solution was stirred at room temperature for 24 hours, during which time the product precipitated as a white fluffy solid. The mixture was cooled to $0{ }^{\circ} \mathrm{C}$, filtered under reduced pressure, and the collected solid dried under vacuum to yield the benzyl ammonium salt $\mathbf{I}\left[4-\mathrm{Br}\left(\mathrm{C}_{6} \mathrm{H}_{4}\right) \mathrm{CH}_{2} \mathrm{NEt}_{3}\right][\mathrm{Br}](3.67 \mathrm{~g}$, yield $85 \%$ ) as a white fluffy solid. A salt metathesis was performed with $\mathrm{NaPF}_{6}$ by mixing a saturated aqueous solution of $\mathbf{I}(3.54 \mathrm{~g}, 10 \mathrm{mmol})$ with a saturated aqueous solution of $\mathrm{NaPF}_{6}$ and stirring for $30 \mathrm{~min}$, followed by filtration and dryness under vacuum to produce $1\left[4-\mathrm{Br}\left(\mathrm{C}_{6} \mathrm{H}_{4}\right) \mathrm{CH}_{2} \mathrm{NEt}_{3}\right]\left[\mathrm{PF}_{6}\right]\left(2.727 \mathrm{~g}\right.$, yield $65 \%$ ). ${ }^{1} \mathrm{H}$ NMR $(300 \mathrm{MHz}$, DMSO$\left.d_{6}\right): \delta(\mathrm{ppm}): 7.71(\mathrm{~d}, 2 \mathrm{H}, J=8.4 \mathrm{~Hz}), 7.47(\mathrm{~d}, 2 \mathrm{H}, J=8.4 \mathrm{~Hz}), 4.48(\mathrm{br} \mathrm{s}, 2 \mathrm{H}), 3.15(6 \mathrm{H}, 4, J=7.4 \mathrm{~Hz}), 1.28$ $(9 \mathrm{H}, \mathrm{t}, J=7.4 \mathrm{~Hz}) \cdot{ }^{13} \mathrm{C}$ NMR $\left(75 \mathrm{MHz}, \mathrm{DMSO}-d_{6}\right): \delta(\mathrm{ppm}): 134.7(\mathrm{CH}), 131.9(\mathrm{CH}), 127.1(\mathrm{C}), 123.9(\mathrm{C})$, 66.6 $\left(\mathrm{CH}_{2}\right), 58.6\left(\mathrm{CH}_{2}\right), 7.44\left(\mathrm{CH}_{3}\right)$. LR-ESI-MS/MS (m/z \% rel. int.): $270.3[\mathrm{M}]^{+}, 36 ; 169.1\left[\mathrm{M}-\mathrm{NEt}_{3}\right]^{+}$, $100 ; 100.3\left[\mathrm{M}-\mathrm{C}_{7} \mathrm{H}_{7} \mathrm{Br}\right]^{+}, 32$.

Compound 2 (4-bromo-N,N,N-trimethyl-benzeneaminium hexafluorophosphate) was synthesized according to the literature [31] with some modifications (Scheme 2). To a $250 \mathrm{~mL}$ sealed round-bottom 
flask, 4-bromo-N,N-dimethyl-aminebenzene (3,082 g, $15.4 \mathrm{mmol})$, acetone (100 mL), and methyl iodide $(2.8 \mathrm{~mL}, 6.384 \mathrm{~g}, 44.9 \mathrm{mmol})$ were added. The reaction was stirred overnight at $70{ }^{\circ} \mathrm{C}$ under a nitrogen atmosphere. The reaction mixture was filtered under reduced pressure and the collected solid washed with ice-cold acetone and dried under vacuum overnight to afford compound II $\left[4-\mathrm{Br}\left(\mathrm{C}_{4} \mathrm{H}_{6}\right) \mathrm{NMe}_{3}\right][\mathrm{I}](4.616 \mathrm{~g}$, yield $88 \%$ ) as a white fluffy solid. A salt metathesis was performed with $\mathrm{NaPF}_{6}$ mixing a saturated aqueous solution of II $(4.052 \mathrm{~g}, 11.8 \mathrm{mmol})$ with a saturated aqueous solution of $\mathrm{NaPF}_{6}$ and stirring for $30 \mathrm{~min}$ to give product $2\left[4-\mathrm{Br}\left(\mathrm{C}_{6} \mathrm{H}_{4}\right) \mathrm{NMe}_{3}\right]\left[\mathrm{PF}_{6}\right]\left(1.962 \mathrm{~g}\right.$, yield 46\%). ${ }^{1} \mathrm{H}$ NMR $\left(300 \mathrm{MHz}, \mathrm{DMSO}-d_{6}\right): \delta$ (ppm): 7.95 (d, 2H, J=8.6 Hz), 7.85 (d, 2H, J=8.6 Hz), 3.59 (s, 9H). ${ }^{13} \mathrm{C}$ NMR (75 MHz, DMSO-d 6 ): $\delta$ (ppm): 146.6 (C), $132.7(\mathrm{CH}), 122.8(\mathrm{CH}), 122.0(\mathrm{C}), 56.4\left(\mathrm{CH}_{3}\right)$. LR-ESI-MS/MS (m/\% \% rel. int.): 214.2 [M] ${ }^{+}, 30 ; 199.2$ $[\mathrm{M}-\mathrm{Me}]^{+}, 100 ; 198.3\left[\mathrm{M}-\mathrm{CH}_{4}\right]^{+}, 80$.

Compound 3 (trans-3-(p-benzyl-4-phenyl-3-methoxycarbonyl- $\gamma$-butyrolactone) was synthesized as previously reported by Le Floch and co-workers (Scheme 2) [28]. Briefly, zinc dust (3.0 g, $46 \mathrm{mmol}$ ) was added to a dried $100-\mathrm{mL}$ round-bottomed flask previously flushed with argon and charged with acetonitrile $(20 \mathrm{~mL})$. Dimethyl itaconate $(7.9 \mathrm{~g}, 50 \mathrm{mmol})$, benzaldehyde $(1.0 \mathrm{~mL}, 10 \mathrm{mmol})$, and an aryl bromide (15 mmol; bromobenzene, $2.35 \mathrm{~g}, 1.57 \mathrm{~mL}$ for compound 3) were added whilst stirring. Next, cobalt bromide $(0.44 \mathrm{~g}, 2 \mathrm{mmol})$, trifluoroacetic acid $(0.1 \mathrm{~mL})$, and 1,2-dibromoethane $(0.2 \mathrm{~mL})$ were added successively to the mixture, which was heated to $60{ }^{\circ} \mathrm{C}$ for $2 \mathrm{~h}$. The reaction mixture was filtered through Celite, which was exhaustively washed with diethyl ether. The combined organic fractions were concentrated in vacuo. The resulting crude reaction product was purified by flash column chromatography over silica gel (hexane:ethyl acetate $7: 3 \mathrm{v} / \mathrm{v}$ ) to provide a mixture of stereoisomers of the $\gamma$-lactone $\mathbf{3}(1.086$ g, 35\% yield) as a white powder. ${ }^{1} \mathrm{H}$ NMR $\left(\mathrm{CDCl}_{3}\right): \delta(\mathrm{ppm}) 7.45(2 \mathrm{H}, \mathrm{m}, \mathrm{H}-11$ and $\mathrm{H}-17), 7.43(2 \mathrm{H}, \mathrm{m}$, H-16 and H-18), 7.35 (2H, m, H-15 and H-19), 7.23 (2H, m, H-10 and H-12), 6.95 (2H, m, H-9 and H13), 5.67 (1H, s, H-4), 3.75 (3H, s, H-6), 3.12 (1H, d, $\left.J_{2 \mathrm{~b}, 2 \mathrm{a}}=17.6, \mathrm{H}-2 \mathrm{~b}\right), 2.86$ (1H, d, $\left.J_{7 \mathrm{~b}, 7 \mathrm{a}}=13.9, \mathrm{H}-7 \mathrm{~b}\right), 2.71$ $\left(1 \mathrm{H}, \mathrm{d}, J_{2 \mathrm{a}, 2 \mathrm{~b}}=17.6, \mathrm{H}-2 \mathrm{a}\right), 2.17\left(1 \mathrm{H}, \mathrm{d}, J_{7 \mathrm{a}, 7 \mathrm{~b}}=13.9, \mathrm{H}-7 \mathrm{a}\right) ;{ }^{13} \mathrm{C} \mathrm{NMR}\left(\mathrm{CDCl}_{3}\right): \delta(\mathrm{ppm}) 174.5(\mathrm{C}, \mathrm{C}-1), 173.0$ (C, C-5), 135.7 (C, C-8), 134.3 (C, C-14), 129.5 (CH, C-9 = C-13), $129.1(\mathrm{CH}, \mathrm{C}-11=\mathrm{C}-17), 128.5(\mathrm{CH}, \mathrm{C}-$ $16=\mathrm{C}-18), 127.3(\mathrm{CH}, \mathrm{C}-10=\mathrm{C}-12), 126.5(\mathrm{CH}, \mathrm{C}-15=\mathrm{C}-19), 85.7(\mathrm{CH}, \mathrm{C}-4), 56.3(\mathrm{C}, \mathrm{C}-3), 52.9\left(\mathrm{CH}_{3}\right.$, 
C-6), $39.0\left(\mathrm{CH}_{2}, \mathrm{C}-7\right), 35.6\left(\mathrm{CH}_{2}, \mathrm{C}-2\right)$; ESI-MS m/ z (\% rel. int.) $311[\mathrm{M}+\mathrm{H}]^{+}, 15 ; 293\left[\mathrm{M}+\mathrm{H}-\mathrm{H}_{2} \mathrm{O}\right]^{+}, 10$; $279[\mathrm{M}+\mathrm{H}-\mathrm{MeOH}]^{+}, 50 ; 251[\mathrm{M}+\mathrm{H}-\mathrm{MeOH}-\mathrm{CO}]^{+}, 10 ; 261\left[\mathrm{M}+\mathrm{H}-\mathrm{H}_{2} \mathrm{O}-\mathrm{MeOH}\right]^{+}, 80 ; 233\left[\mathrm{M}+\mathrm{H}-\mathrm{H}_{2} \mathrm{O}-\right.$ $\left.\mathrm{C}_{2} \mathrm{H}_{4} \mathrm{O}_{2}\right]^{+}, 100$.

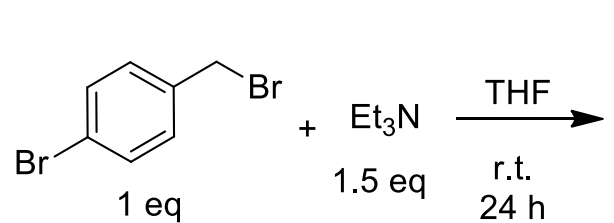<smiles>CC(=O)CC1(C)CCCCC1</smiles>

1 eq<smiles>CC[N+](Br)(CCNC(=O)O)Cc1ccc(Br)cc1</smiles><smiles>C[N+](C)(C)c1ccc(Br)cc1</smiles><smiles>CC[N+](CC)(CC)Cc1ccc(Br)cc1</smiles>

1<smiles>C[N+](C)(C)c1ccc(Br)cc1</smiles>

2<smiles>COC(=O)C1(Cc2ccccc2)CC(=O)OC1c1ccccc1</smiles>

3

Scheme 2. Synthesis of the charge-tagged compounds $\mathbf{1}$ and $\mathbf{2}$ and $\gamma$-lactone $\mathbf{3}$.

\subsection{MCR monitoring by FTIR}

Fourier transform-infrared (FTIR) experiments were performed on Bruker Alpha FTIR in a Harrick demountable transmission flow cell with $\mathrm{BaF}_{2}$ windows, a $100 \mu \mathrm{m}$ path length and a $5 \mu \mathrm{L}$ cell volume. Prior to the MCR investigation, a series of benzaldehyde and $\gamma$-lactone $\mathbf{3}$ solutions in acetonitrile were prepared by two-fold serial dilution and a calibration curve was plotted based on absorption bands at 1704 $\mathrm{cm}^{-1}$ and $1791 \mathrm{~cm}^{-1}$, respectively, which corresponding to their carbonyl stretching. A background spectrum using acetonitrile was recorded before running the experiments. Next, $100 \mu \mathrm{L}$ aliquots were sampled from the reaction mixture every $10 \mathrm{~min}, 15 \mathrm{~min}$, or $30 \mathrm{~min}$ for 6 hours. An initial sample was also collected at 5 min. Acetonitrile was added to these samples to make them up to $1 \mathrm{~mL}$. The samples were filtered using a Pasteur pipet with cotton, transferred to $3 \mathrm{~mL}$ vials and added to $1 \mathrm{~mL} \mathrm{MeCN}$. Finally, a $10 \mu \mathrm{L}$ aliquot of 
this sample was transferred to an Eppendorf vial, diluted to $1 \mathrm{~mL}$ acetonitrile and then introduced onto the IR cell using a $1 \mathrm{~mL}$ syringe. Data were processed using a Bruker Opus Viewer 6.5 software.

\subsection{MCR monitoring by ESI-MS}

The on-line mass spectrometric monitoring of the like-Barbier cobalt catalyzed MCR was performed using PSI-ESI-MS. Briefly, a flask containing the reaction mixture was placed next to the ESI ion source and connected to a source of inert gas by means of a small rubber tube [32]. A PEEK tube was inserted into the Schlenk flask through a rubber septum, with one of the ends immersed into the reaction mixture and the other connected to the ESI source inlet. A slight overpressure (between 1 and 4 psi) was applied to facilitate continuous sample introduction through the PEEK tube into the mass spectrometer. To minimize PEEK or ESI capillary clogging issues, a cotton filter was fitted to the PEEK tip that was immersed into the reaction mixture. All the experiments were performed on a Waters Acquity Triple Quadrupole Detector (TQD). The instrument parameters employed were as follows: capillary voltage, 3.0 $\mathrm{kV}$, cone voltage, $15 \mathrm{~V}$, extraction voltage, $3.0 \mathrm{~V}$; source temperature $90{ }^{\circ} \mathrm{C}$, gas flow rate, $100 \mathrm{~L} / \mathrm{h}$; desolvation gas flow rate, $100 \mathrm{~L} / \mathrm{h}$. Scan time was $5 \mathrm{~s}$.

For the off-line monitoring experiments, $100 \mu \mathrm{L}$ aliquots were sampled from the reaction mixture. Acetonitrile was added to these samples to make them up to $1 \mathrm{~mL}$. Next, these samples were filtered using a Pasteur pipet with cotton, then transferred to 3-mL vials and then added to $1 \mathrm{~mL}$ MeCN. Finally, a 10 $\mu \mathrm{L}$ aliquot of this sample was transferred to an Eppendorf vial, diluted to $1 \mathrm{~mL}$ acetonitrile and then introduced into the ESI source with a $1 \mathrm{~mL}$ analytical syringe connected to PEEK tubing and a syringe pump at a flow rate of $30 \mu \mathrm{L} / \mathrm{min}$.

Product ion spectra of the selected precursor ions were recorded by collision-induced dissociation (CID) with argon gas $(99.999 \%)$ at energies $\left(\mathrm{E}_{\text {lab }}\right)$ ranging between 5 and $40 \mathrm{~V}$. 


\section{Results and discussion}

\subsection{FTIR MCR monitoring}

Le Floch and co-workers have reported that the like-Barbier cobalt catalyzed MCR using benzaldehyde (10 mmol, 1 eq), dimethyl itaconate ( $50 \mathrm{mmol}, 5$ eq to benzaldehyde), bromobenzene (15 mmol, 1.5 eq to benzaldehyde), zinc dust (46 mmol, 3 eq to bromobenzene), and cobalt bromide ( 2 mmol, $15 \mathrm{~mol} \%$ to bromobenzene) go to completion in about 2 hours at $60{ }^{\circ} \mathrm{C}$ under conventional heating. Pinato-Botelho and co-workers employed the same conditions under microwave heating and obtained a shorter reaction time [33]. Thus, before starting the MCR monitoring using mass spectrometry, we monitored this reaction by FTIR under the same experimental conditions reported by Le Floch and coworkers (Figure 1). In this study, appearance of the lactone product had a half-life under normal reaction conditions of approximately 11.4 minutes. However, under much more dilute conditions, which are needed for PSI-ESI-MS experiments to prevent saturation effects [34] and instrumental contamination [19], the reaction does not proceed significantly within 2 hours. These results led us to monitor the MCR off-line by ESI-MS.

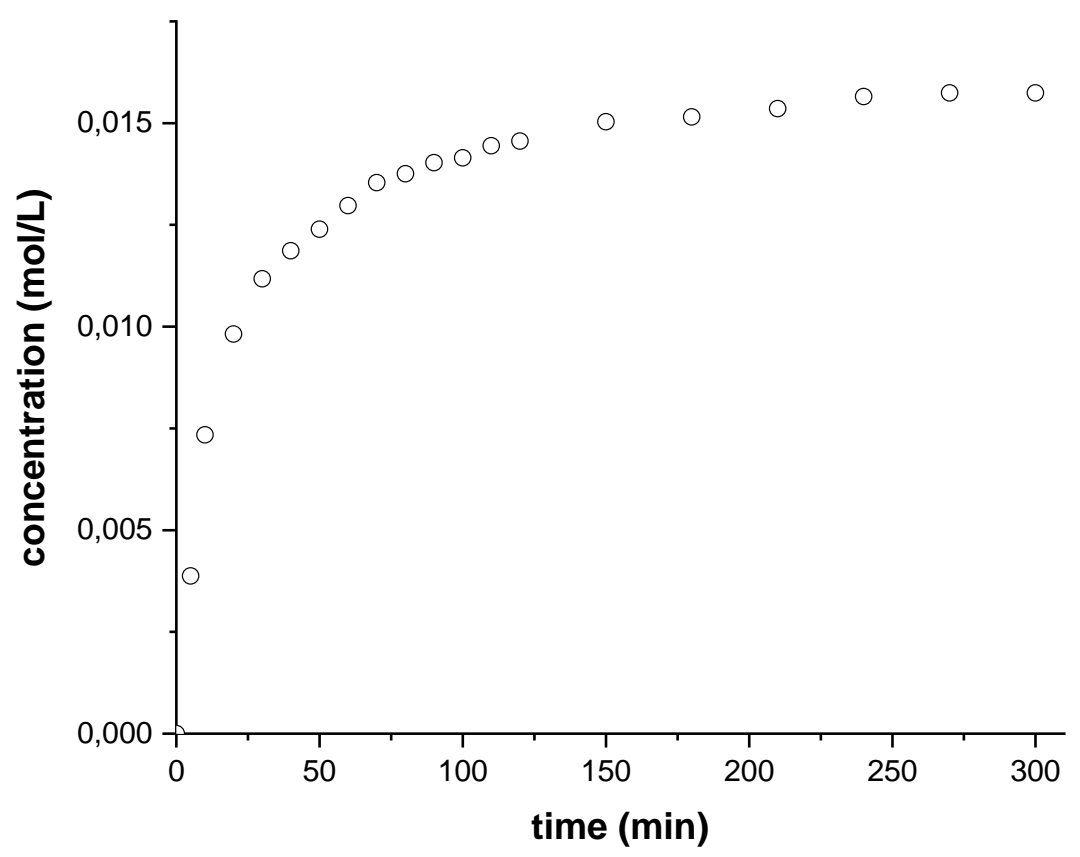

Figure 1. Changes in the benzaldehyde $\left(1704 \mathrm{~cm}^{-1}\right)$ and $\gamma$-lactone $3\left(1791 \mathrm{~cm}^{-1}\right)$ concentrations (mmol/L) over time (min), as monitored by FTIR. 


\subsection{MCR off-line monitoring using ESI-MS and ESI-MS/MS}

We monitored the MCR with dimethyl itaconate, benzaldehyde, and bromobenzene (Scheme 1) under the same conditions as reported in the literature (stoichiometry, concentrations, the order of addition, and temperature) [28], except for the addition of charge-tagged aryl halides 1 or $\mathbf{2}(0.2 \mathrm{mmol})$ as co-reagents. Aliquots were sampled from the reaction mixture every $5 \mathrm{~min}, 15 \mathrm{~min}$, or $60 \mathrm{~min}$ for $6 \mathrm{~h}$, filtered, diluted, and then injected directly into the ESI source by a syringe.

Peaks corresponding to the expected charge tagged $\gamma$-lactones at $m / z 424$ (for charge tagged 1 ) and $m / z 368$ (for charge tagged 2 ) were observed in the MS spectra from $t=10$ min (Figure 2). Product ion spectra of $m / z 424$ and $m / z 368$ and the formation of their main product ions are given in Figures 3 and 4. Their relative intensities did not increase in the mass spectra obtained after 10 min, likely due to their reduced solubilities in acetonitrile. However, the most intense peaks in the mass spectra were assigned to cobalt and zinc complexes with acetonitrile, and dimethyl itaconate, which was used in excess. These peaks were assigned on the basis of their product ion spectrum, isotopic pattern, and reaction behavior, as will be discussed later. Peaks of $m / z 192$ and $m / z 136$ are also intense in the mass spectra (Figure 2). Analysis of the product ion spectrum of $\mathrm{m} / \mathrm{z}_{1} 192$ and $\mathrm{m} / \mathrm{z}_{1} 136$ revealed that they are derived from the charge tagged aryl halides 1 and 2, respectively (Figures 3 and 4). Peaks corresponding to possible reaction intermediate were not observed or could not be distinguished from the background. 

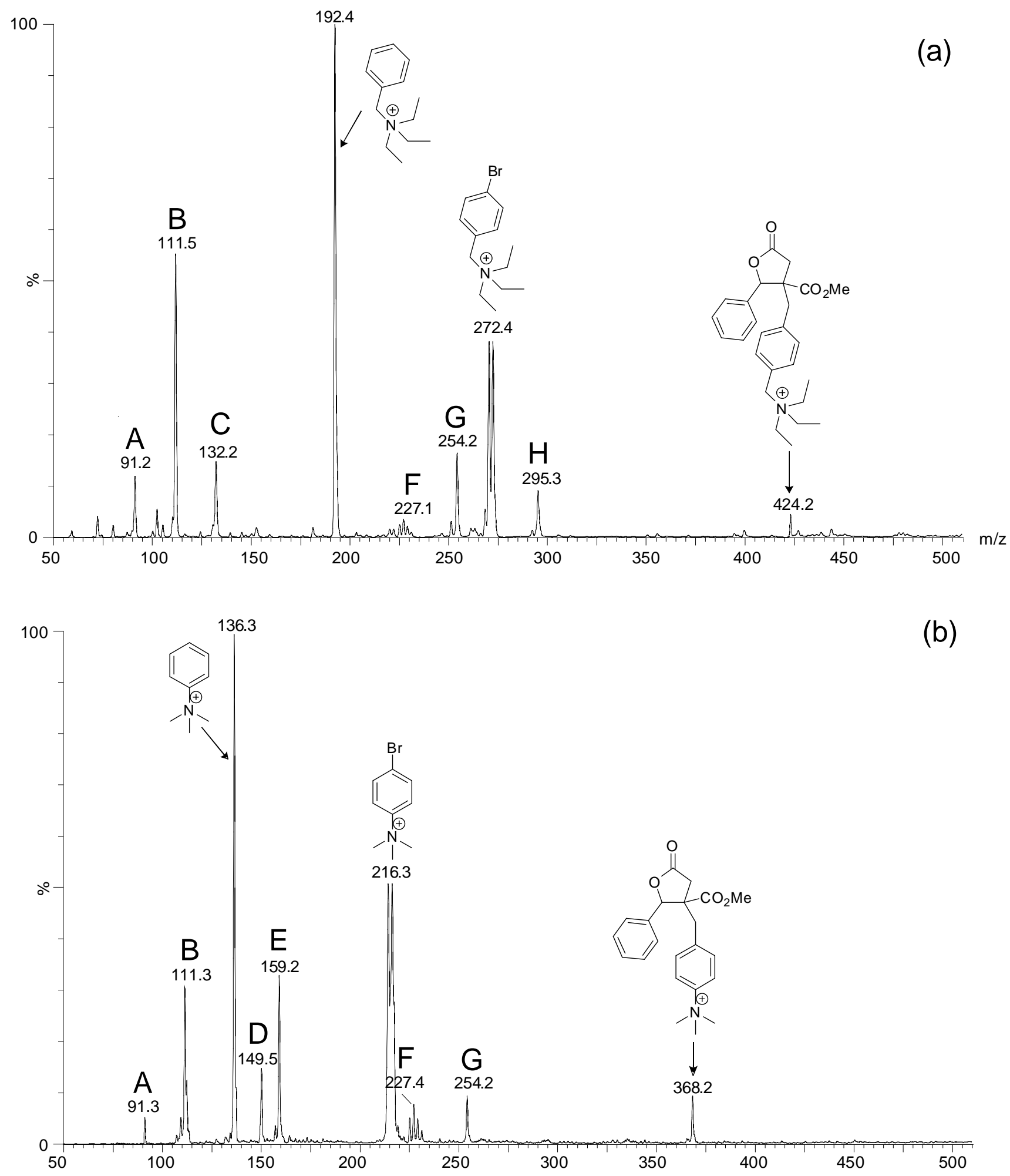

Figure 2. ESI-MS spectrum of the MCR mixture sampled at 10 min from two different experiments under literature conditions, added to charge tagged compounds $\mathbf{1}$ (a) and $\mathbf{2}(\mathrm{b})$ as co-reagents. A: $\left[\mathrm{Co}(\mathrm{MeCN})_{3}\right]^{2+}$; B: $\quad\left[\mathrm{Co}(\mathrm{MeCN})_{4}\right]^{2+} ; \quad \mathbf{C}: \quad\left[\mathrm{Co}(\mathrm{MeCN})_{6}\right]^{2+} ; \quad \mathbf{D}: \quad\left[\mathrm{Co}\left(\mathrm{C}_{7} \mathrm{H}_{10} \mathrm{O}_{4}\right)(\mathrm{MeCN})\right]^{2+} ; \quad \mathbf{E}: \quad\left[\mathrm{C}_{7} \mathrm{H}_{10} \mathrm{O}_{4}+\mathrm{H}\right]^{+} ; \quad$ F: $\left.\left[\mathrm{ZnBr}(\mathrm{MeCN})_{3}\right]+; \mathbf{G}:\left[\mathrm{Co}\left(\mathrm{CF}_{3} \mathrm{CO}_{2}\right)(\mathrm{MeCN})_{2}\right]^{+} ; \mathbf{H}: \mathrm{Co}\left(\mathrm{CF}_{3} \mathrm{CO}_{2}\right)(\mathrm{MeCN})_{3}\right]^{+}$. 


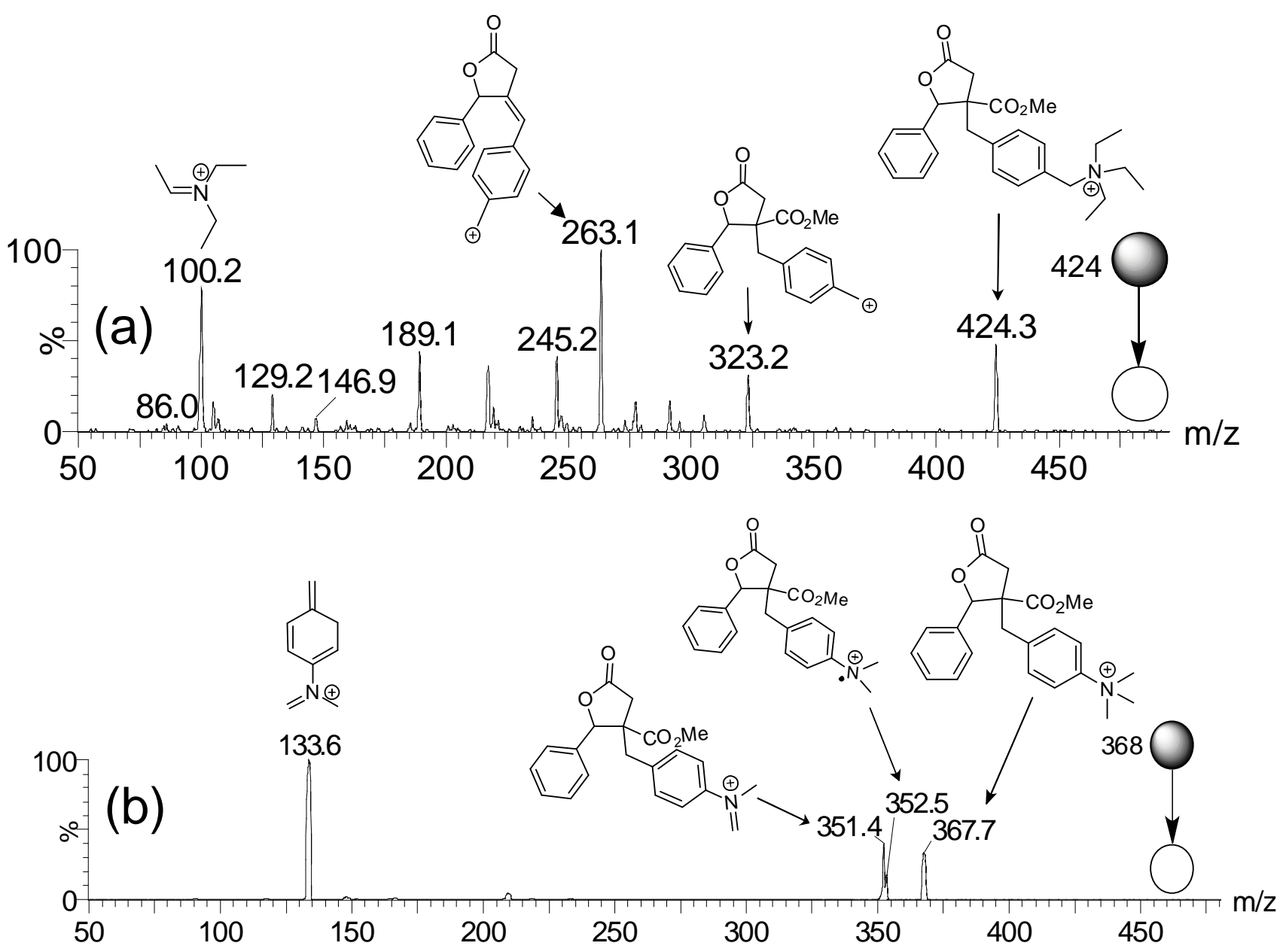

Figure 3. Product ion spectrum of $m / z, 424$ (a) and $m / z 368$ (b) (Ar, $\mathrm{E}_{\text {lab }}=10 \mathrm{eV}$ ) and structure of some their product ions. 

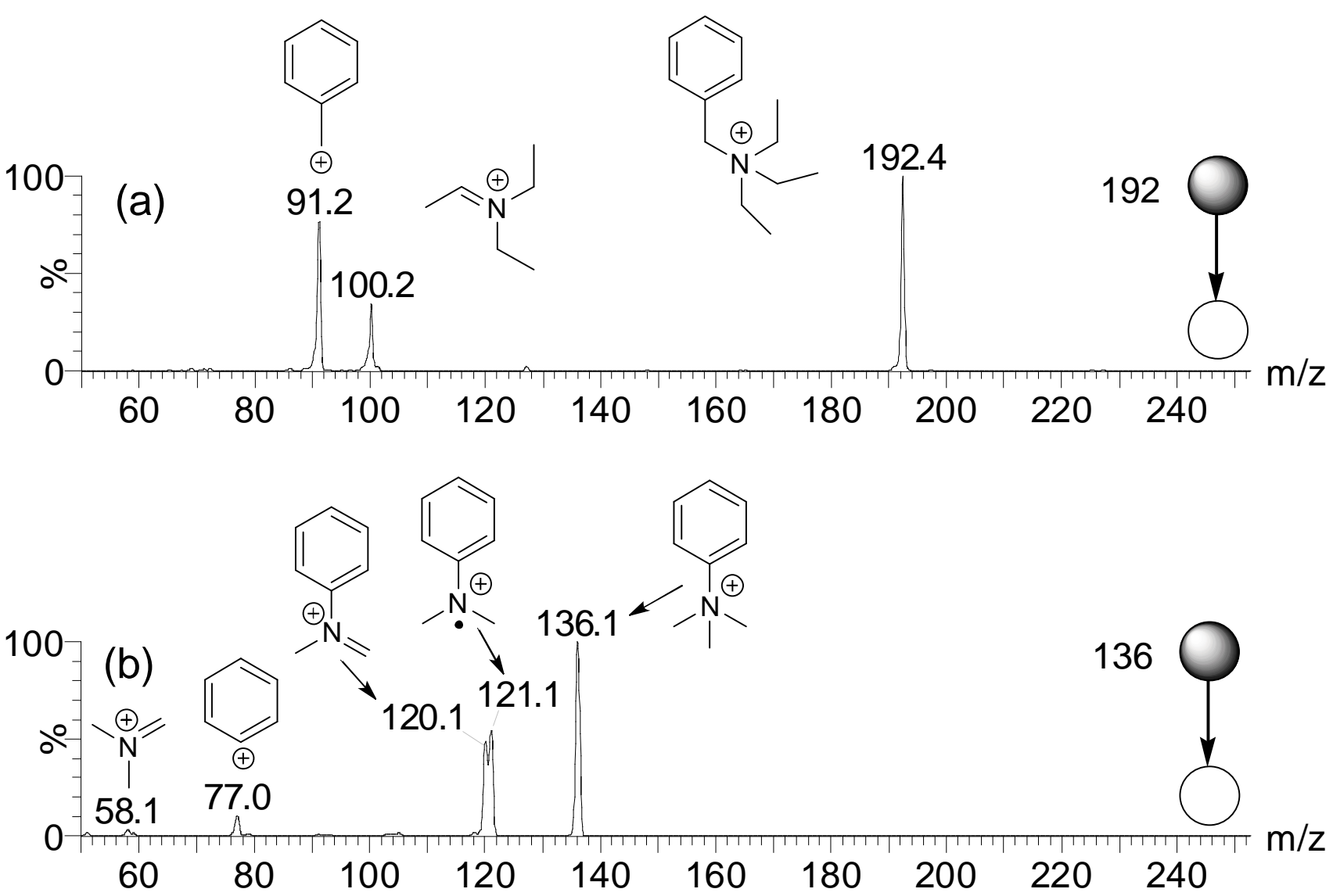

Figure 4. Product ion spectrum of $m / z 192$ (a) and $m / z 136$ (b) (Ar, Elab=10 eV) and formation of some of their product ions.

\subsection{MCR online monitoring using PSI-ESI-MS}

Because there is no previous reports in the literature for the formation of species similar to those of $m / z 136$ and $m / z 192$ in this MCR, we decided to recur to PSI-ESI-MS to track the changes in the reaction mixture composition in the first 2 hours of reaction to better understand the formation of these ions.

Our initial PSI-ESI-MS experiments were carried out without adding charge-tagged aryl halides. To minimize clogging, as well as to avoid detector saturation issues, the reagents and catalyst amounts used were fifty times lower as compared to literature [28], as follows: dimethyl itaconate (1 mmol), aryl halide (0.3 mmol), aromatic aldehyde $(0.2 \mathrm{mmol})$, zinc dust $(0.92 \mathrm{mmol})$, cobalt bromide $(0.04 \mathrm{mmol})$, TFA (2 $\mu \mathrm{L}$ ), and DBE $(4 \mu \mathrm{L})$. To ensure good ESI-MS performance, $20 \mathrm{~mL}$ acetonitrile was used. In all the 
experiments, a Schlenk flask containing zinc dust was purged with argon and then added to $20 \mathrm{~mL}$ of scrupulously dried acetonitrile. Next, the chemicals were added following the same order of addition as literature (dimethyl itaconate, benzaldehyde, aryl halide, $\mathrm{CoBr}_{2}$, TFA, and DBE, in this sequence). Most of the reagents did not cause any significant increase in the total ion count. However, a large number of intense new peaks that were not observed in the off-line monitoring with charge-tagged aryl halides $\mathbf{1}$ and 2 appeared after cobalt(II) bromide addition. Thus, an experiment was designed to assign peaks corresponding to cobalt(II) complexation to acetonitrile and other chemicals. For this purpose, $\mathrm{CoBr}_{2}$ was added to the Schlenk flask containing acetonitrile only, so that the arising peaks were assigned to cobalt(II) complexes with acetonitrile. Benzaldehyde was added followed by dimethyl itaconate. A figure displaying this strategy and a list of peaks assigned to cobalt(II) complexes on the basis of this experiment are given in the Supporting Information. Peaks due to possible intermediates were not evident, likely due to their signal suppression by the cobalt(II) complex signals. As expected, peaks of $\mathrm{m} / \mathrm{z} 136 \mathrm{or} \mathrm{m} / \mathrm{z} 192$ were not observed (charged tagged aryl halides 1 and $\mathbf{2}$ were not used in these experiments).

Next, to increase the signals of possible MCR intermediate, PSI-ESI-MS experiments using charge tagged aryl halides $1(0.3 \mathrm{mmol})$ and $\mathbf{2}(0.3 \mathrm{mmol})$ were performed. In these cases, resolution was a particular challenging issue; decreased resolution led to detector saturation, whereas increased resolution reduced the sensitivity and compromised detection of the lower intensity species. In summary, peaks of possible reaction intermediate were suppressed by the charge tagged compound signals and $\mathrm{m} / \mathrm{z} 192$ (for charge tagged $\mathbf{1}$ ) or $m / z 136$ (for charged tag 2). Alternatively, under diluted conditions, the intermediates could be quenched by the solvent, then not forming the expected product.

Because we have used diluted conditions in our PSI-ESI-MS experiments, it was already expected from FTIR results that the reaction will not go to completion in 2 hours. However, analysis of the TIC traces of the charge tagged compounds $1\left(\mathrm{~m} / \mathrm{z}^{270)}\right.$ and $\mathbf{2}(\mathrm{m} / \mathrm{z} 214)$ revealed that their relative intensities decreased over 2 hours, whereas signals of the intermediate and the expected charge tagged $\gamma$ lactones $(m / z 424$ and $m / z 368)$ were not detected. On the other hand, the $m / z 192$ and $m / z 136$ peak 
intensities increased in the same period. We decided to compare changes in the charge tagged $\mathbf{1}$ and $\mathbf{2}$ signal intensities with those of $m / z 192$ and $m / z 136$. As shown in Figure 5, $m / z^{270}$ and $m / z^{214}$ signal intensities started decreasing after cobalt(II) addition, whereas peaks of $m / z 192$ and $m / z 136$ arise after cobalt(II) addition to the reaction mixture. These results revealed that $m / z, 192$ and $m / z, 136$ are cobalt-promoted hydrodehalogenation products, which are formed from the charge tagged aryl halides $1\left(\mathrm{~m} / \mathrm{z}^{2} \mathrm{270}\right)$ and 2 $\left(m / z^{214}\right)$, respectively. In addition, these results provided pieces of evidence to refute the hypothesis that these ions could be due to quenching of the organometallic species by a proton source from the reaction mixture (e. g., TFA), added to the fact that these peaks emerged in the mass spectrum even when TFA was not used. 

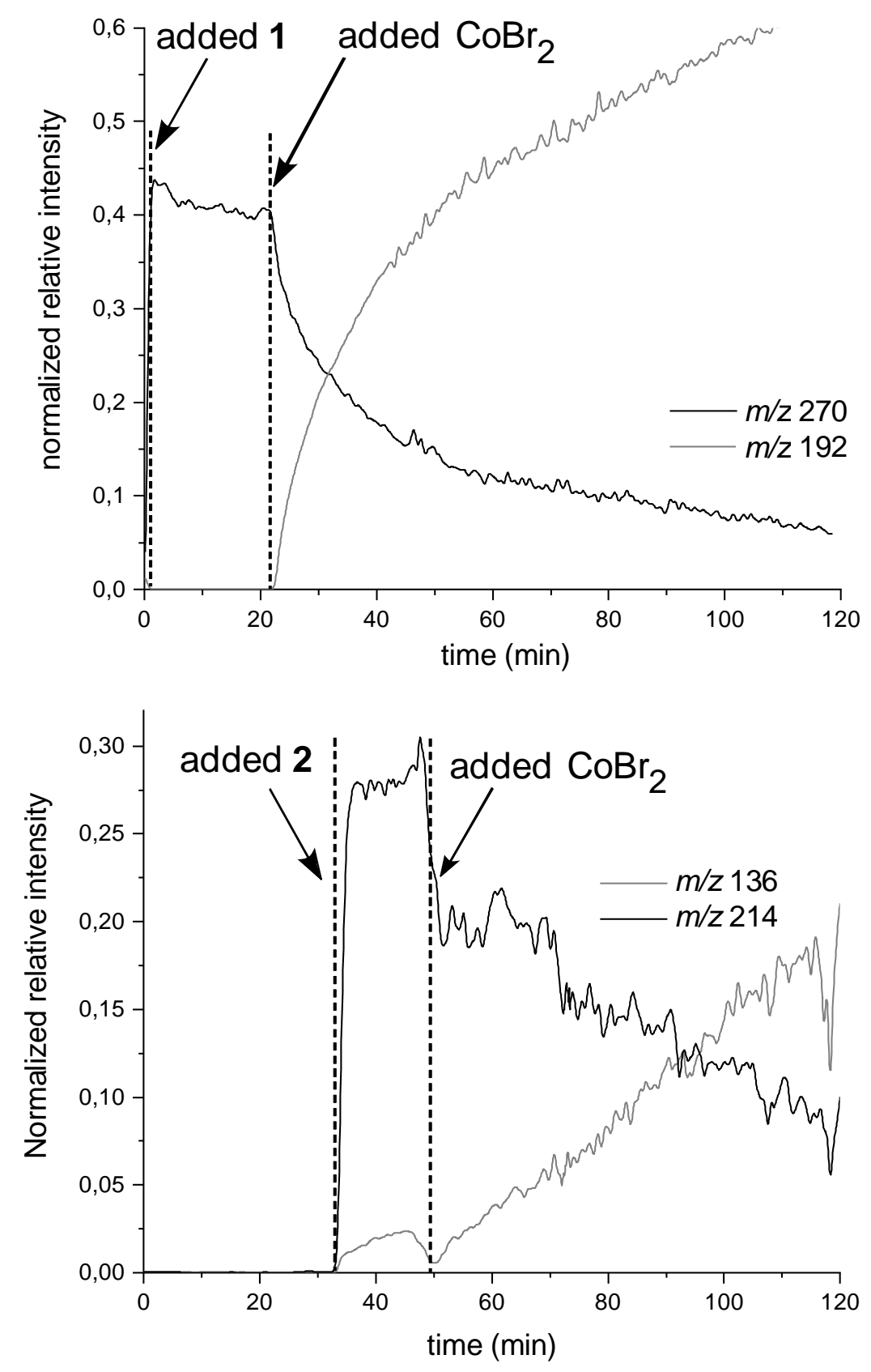

Figure 5. Changes in the normalized relative abundances of $\mathrm{m} / \mathrm{z} 270$ and 192 (a) and $\mathrm{m} / \mathrm{z} 214$ and 136 (b) over time, as monitored by PSI-ESI-MS.

Le Gall and co-workers have proposed and extensively studied the cobalt(II)-mediated onepot transition metal-catalyzed multicomponent reaction investigated herein. Initially, the authors proposed that an organocobalt species is a key intermediate in the mechanism of this MCR by favoring the conjugate addition to dimethyl itaconate and further aldolization-cyclization leading to the formation of the five- 
membered lactone ring. Experimental results revealed that the reaction can be conducted with reducing agents others than zinc (e.g., manganese), thus proving that organozinc formation is not required for the reaction to proceed [28]. More recently, the authors proposed that the reaction is initiated by a cyclometallation of both Michael acceptor (e. g., dimethyl itaconate) and unsaturated electrophile (e.g., benzaldehyde) to a cobalt(I) complex, which would undergo methathesis with the organozinc reagent derived from the aryl halide $(\mathrm{RZnBr})$ to furnish a triorganocobalt(III) species and zinc bromide. After reductive elimination, transmetalation with zinc bromide would furnish a zinc alcoholate precursor of the final compound (formed by protonation), as well as regenerating cobalt(I) for another catalytic cycle [35]. The authors also reported the occurrence of side-reactions for the MCR under study, such as aryl homocoupling and nucleophilic addition of the organometallic to the aromatic aldehyde (Scheme 3). However, although cobalt-promoted dehydrohalogenation has been previously reported in literature [36], its occurrence as side reaction in this MCR has not been previously considered. This byproduct may have been overlooked due to the fact that the dehydrohalogenation products derived from non-charge tagged compounds might have been removed during the isolation process of the $\gamma$-lactones (e.g., benzene derived from bromobenzene can be lost during sample concentration in a rotary evaporator). Here, the dehydrohalogenation products were detected when charge tagged aryl halides 1 and 2 were used both in ESI-MS off-line monitoring and PSI-ESI-MS. The occurrence of hydrodehalogenation as a side reaction in this MCR reinforce the need of using excess of aryl halide (1.5 eq) to aromatic benzaldehyde (1 eq) for obtaining $\gamma$-lactones in good yields. 


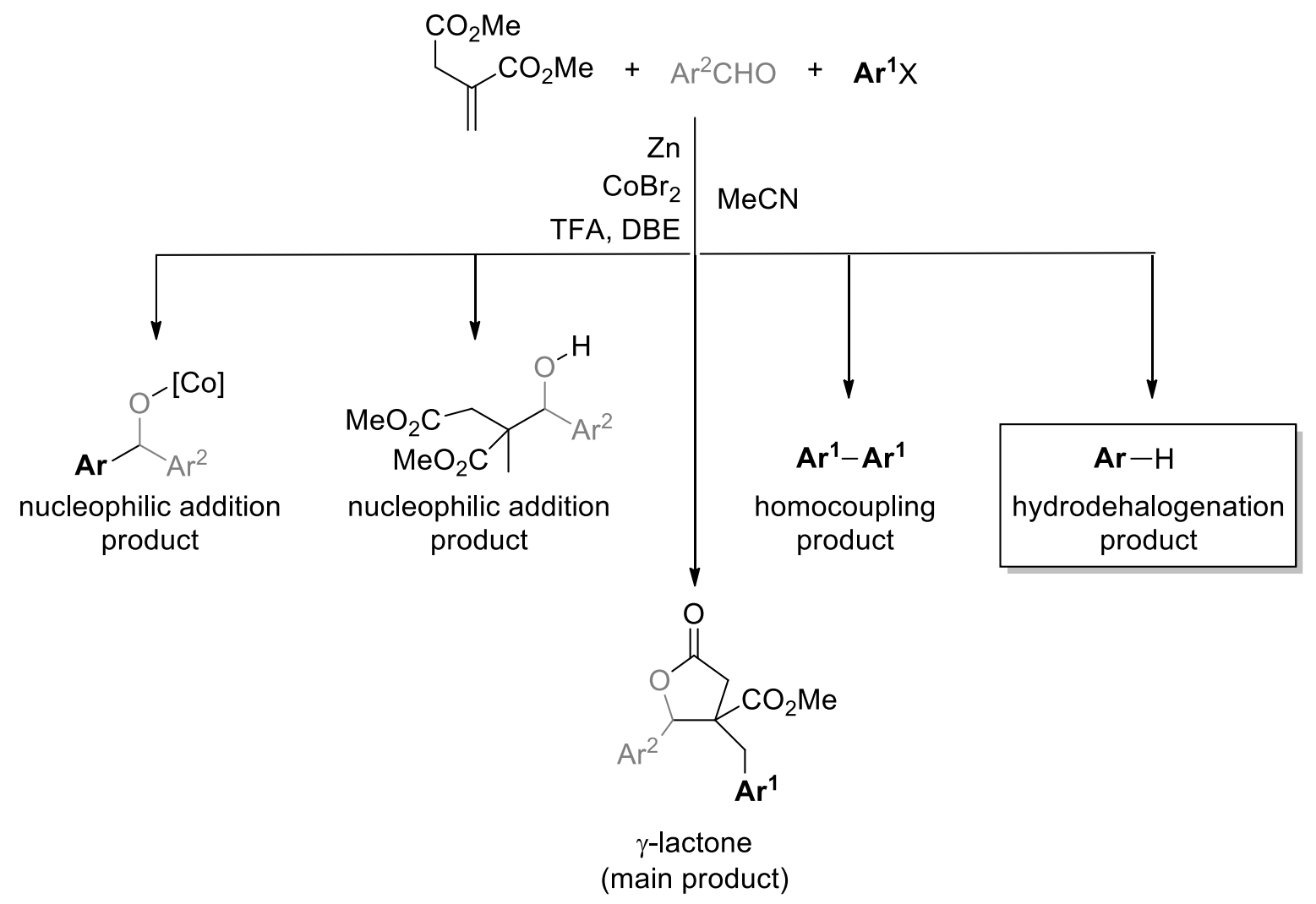

Scheme 3. Overview of the previously reported cobalt(II)-promoted MCR products and byproducts, added to the hydrodehalogenation side-reaction.

\section{Conclusions}

This study demonstrated that the PSI-ESI-MS, which has been employed in many mechanistic studies of homogeneous catalysis can also be used, albeit with increased practical challenges, for real-time monitoring of heterogeneous catalysis. The use of charge tagged aryl halides was crucial for the detection of the hydrodehalogenation product. Although these products were also detected in the ESI-MS off-line monitoring, the ability of PSI-ESI-MS to track real-time changes in the reaction mixture composition afforded important pieces of evidence for formation of these products only after cobalt(II) addition. The occurrence of cobalt(II)-promoted hydrodehalogenation as a side reaction in this MCR had not been considered in previous mechanistic proposals and represents an important piece of its global mechanism. On the other hand, the high signal intensities of the the hydrodehalogenation products in the mass spectrum, as well as the high intensity of cobalt(II) complexes with acetonitrile and other species in 
solution, especially in the diluted conditions needed for PSI-ESI-MS experiments, supress the signals of mechanistically important intermediate species and hampered to obtain a more complete picture of this MCR mechanism.

\section{CRediT authorship contribution statement}

Antonio Crotti: Conceptualization, Investigation, Writing - original draft; Writing - review \& editing. Daniel Previdi: Investigation; Writing - original draft. Paulo Donate: Conceptualization, Writing original draft. Scott McIndoe: Conceptualization, Resources, Supervision, Writing - review \& editing.

\section{Declaration of Competing Interest}

The authors declare that they have no known competing financial interests or personal relationships that could have appeared to influence the work reported in this paper.

\section{Acknowledgements}

A.E.M.C. thanks the Brazilian foundation Fundação de Amparo à Pesquisa do Estado de São Paulo (FAPESP, grant number 2016/03036-4). The authors thank the University of Victoria for infrastructural support.

\section{Supplementary data}

Supplementary data to this article can be found online.

\section{References}

[1] Schroder, D. Applications of electrospray ionization mass spectrometry in mechanistic studies and catalysis research. Acc. Chem. Res. 2012, 45, 1521-1532. 
[2] Santos, L. S.; Rosso, G. B.; Pilli, R. A.; Eberlin, M. N. The mechanism of the Stille reaction investigated by electrospray ionization mass spectrometry. J. Org. Chem. 2007, 72, 5809-5812.

[3] Milagre, C. D. F.; Milagre, H. M. S.; Santos, L. S.; Lopes, M. L. A.; Moran, P. J. S.; Eberlin, M. N.; Rodrigues, J. A. R. Probing the mechanism of direct Mannich-type $\alpha$-methylenation of ketoesters via electrospray ionization mass spectrometry. J. Mass Spectrom. 2007, 42, 1287-1293.

[4] Medeiros, G. A.; da Silva, W. A.; Bataglion, G. A.; Ferreira, D. A. C.; de Oliveira, H. C. B.; Eberlin, M. N.; Neto, B. A. D. Probing the mechanism of the Ugi four-component reaction with charge-tagged reagents by ESI-MS(/MS). Chem. Commun. 2014, 50, 338-340.

[5] Sabino, A. A.; Machado, A. H. L.; Correia, C. R. D.; Eberlin, M. N. Probing the mechanism of the Heck reaction with arene diazonium salts by electrospray mass and tandem mass spectrometry. Angew. Chem. Int. Ed. 2004, 43, 2514-2518.

[6] Oliveira, F. F. D.; dos Santos, M. R.; Lalli, P. M.; Schmidt, E. M.; Bakuzis, P.; Lapis, A. A. M.; Monteiro, A. L.; Eberlin, M. N.; Neto, B. A. D. Charge-tagged acetate ligands as mass spectrometry probes for metal complexes investigations: applications in Suzuki and Heck phosphine-free reactions. J. Org. Chem 2011, 76, 10140-10147.

[7] Vikse, K. L.; Ahmadi, Z.; Manning, C. C.; Harrington, D. A.; McIndoe, J. S. Powerful insight into catalytic mechanisms through simultaneous monitoring of reactants, products, and intermediates. Angew. Chem. Int. Ed. 2011, 50, 8304-8306.

[8] Amarante, G. W.; Milagre, H. M. S.; Vaz, B. G.; Ferreira, B. R. V.; Eberlin, M. N.; Coelho, F. Dualistic nature of the mechanism of the Morita-Baylis-Hillman reaction probed by electrospray iionization mass spectrometry. J. Org. Chem. 2009, 74, 3031-3037.

[9] Santos, L. S.; Neto, B. A. D.; Consorti, C. S.; Pavam, C. H.; Almeida, W. P.; Coelho, F.; Dupont, J.; Eberlin, M. N. The role of ionic liquids in co-catalysis of Baylis-Hillman reaction: Interception of supramolecular species via electrospray ionization mass spectrometry. J. Phys. Org. Chem. 2006, 19, 731-736. 
[10] Meurer, E. C.; Santos, L. S.; Pilli, R. A.; Eberlin, M. N. Probing the mechanism of the Petasis olefination reaction by atmospheric pressure chemical ionization mass and tandem mass spectrometry. Org. Lett. 2003, 5, 1391-1394.

[11] Santos, L. S.; Metzger, J. O. Study of homogeneously catalyzed Ziegler-Natta polymerization of ethene by ESI-MS. Angew. Chem. Int. Ed. 2006, 45, 977-981.

[12] Henderson, M. A.; Luo, J.; Oliver, A.; McIndoe, J. S. The Pauson-Khand reaction: a gas-phase and solution-phase examination using electrospray ionization mass spectrometry. Organometallics 2011, 30, 5471-5479.

[13] Ahmadi, Z.; McIndoe, J. S. A mechanistic investigation of hydrodehalogenation using ESI-MS. Chem. Commun. 2013, 49, 11488-11490.

[14] Fabris, D. Mass spectrometric approaches for the investigation of dynamic processes in condensed phase. Mass Spectrom. Rev. 2005, 24, 30-54.

[15] Vikse, K. L.; Ahmadi, Z.; Luo, J.; van der Wal, N.; Daze, K.; Taylor, N.; McIndoe, J. S. Pressurized sample infusion: An easily calibrated, low volume pumping system for ESI-MS analysis of reactions. Int. J. Mass Spectrom. 2012, 323-324, 8-13.

[16] Vikse, K. L.; Woods, M. P.; McIndoe, J. S. Pressurized sample infusion for the continuous analysis of air- and moisture-sensitive reactions using electrospray ionization mass spectrometry. Organometallics 2010, 29, 6615-6618.

[17] Luo, J.; Oliver, A. G.; Scott McIndoe, J. A detailed kinetic analysis of rhodium-catalyzed alkyne hydrogenation. Dalton Trans. 2013, 42, 11312-11318.

[18] Santos, L. S.; Knaack, L.; Metzger, J. O. Investigation of chemical reactions in solution using API-MS. Int. J. Mass Spectrom. 2005, 246, 84-104.

[19] Yunker, L. P. E.; Ahmadi, Z.; Logan, J. R.; Wu, W.; Li, T.; Martindale, A.; Oliver, A. G.; McIndoe, J. S. Real-time mass spectrometry investigations into the mechanism of the Suzuki-Miyaura reaction. Organometallics 2018, 37, 4297-4308. 
[20] Climent, M. J.; Corma, A.; Iborra, S. Homogeneous and heterogeneous catalysts for multicomponent reactions. RSC Adv. 2011, 2012, 16-58.

[21] Alvim, H. G. O.; da Silva Junior, E. N.; Neto, B. A. D. What do we know about multicomponent reactions? Mechanisms and trends for the Biginelli, Hantzsch, Mannich, Passerini and Ugi MCRs. RSC Adv. 2014, 4, 54282-54299.

[22] Arndtsen, B. A. Metal-catalyzed one-step synthesis: towards direct alternatives to multistep heterocycle and amino acid derivative formation. Chem. Eur. J. 2009, 15, 302-313.

[23] Alvim, H. G. O.; Bataglion, G. A.; Ramos, L. M.; de Oliveira, A. L.; de Oliveira, H. C. B.; Eberlin, M. N.; de Macedo, J. L.; da Silva, W. A.; Neto, B. A. D. Task-specific ionic liquid incorporating anionic heteropolyacid-catalyzed Hantzsch and Mannich multicomponent reactions. Ionic liquid effect probed by ESI-MS(/MS). Tetrahedron 2014, 70, 3306-3313.

[24] Santos, V. G.; Godoi, M. N.; Regiani, T.; Gama, F. H. S.; Coelho, M. B.; de Souza, R. O. M. A.; Eberlin, M. N.; Garden, S. J. The multicomponent Hantzsch reaction: comprehensive mass spectrometry monitoring using charge-tagged reagents. Chem. Eur. J. 2014, 20, 12808-12816.

[25] Souza, R. Y.; Bataglion, G. A.; Ferreira, D. A. C.; Gatto, C. C.; Eberlin, M. N.; Neto, B. A. D. Insights on the Petasis Borono-Mannich multicomponent reaction mechanism. RSC Adv. 2015, 5, 7633776341.

[26] De Souza, R. O. M. A.; da Penha, E. T.; Milagre, H. M. S.; Garden, S. J.; Esteves, P. M.; Eberlin, M. N.; Antunes, O. A. C. The three-component Biginelli reaction: A combined experimental and theoretical mechanistic investigation. Chem. Eur. J. 2009, 15, 9799-9804.

[27] Silva, G. C. O.; Correa, J. R.; Rodrigues, M. O.; Alvim, H. G. O.; Guido, B. C.; Gatto, C. C.; Wanderley, K. A.; Fioramonte, M.; Gozzo, F. C.; de Souza, R. O. M. A.; Neto, B. A. D. The Biginelli reaction under batch and continuous flow conditions: catalysis, mechanism and antitumoral activity. RSC Adv. 2015, 5, 48506-48515. 
[28] Le Floch, C.; Le Gall, E.; Léonel, E.; Koubaa, J.; Martens, T.; Retailleau, P. A cobalt-catalyzed multicomponent approach to novel 2,3-di and 2,2,3-trisubstituted 3-methoxycarbonyl- $\gamma$ butyrolactones. Eur. J. Org. Chem. 2010, 5279-5286.

[29] Amarego, W. L. F.; Chai, C. L. L. Purification of laboratory chemicals, 6 ${ }^{\text {th }}$. Bulrington, MA: Elsevier, 2009.

[30] Roiser, L.; Robiette, R.; Waser, M. Benzylic ammonium ylide mediated epoxidations. Synlett 2016, 27, 1963-1968.

[31] Effenberger, F.; Steinbach, A.; Epple, G.; Hanauer, J. Brom-additionsprodukte von N,Ndialkylanilinen - Darstellung und reaktionen. Chem. Ber. 1983, 116, 3539-3551.

[32] Thomas, G. T.; MacGillivray, L.; Dean, N. L.; Stoddard, R.; Yunker, L. P. E.; McIndoe, J. S. Confounding contaminants in mass spectrometric reaction monitoring. Int. J. Mass Spectrom. 2019, 441, 14-18.

[33] Pinato-Botelho, M. F.; Crotti, A. E. M.; Souza, J. M.; Magalhães, L. G.; Donate, P. M. Microwaveassisted synthesis and antileishmanial activity of 3-methoxycarbonyl- $\gamma$-butyrolactone derivatives. J. Braz. Chem. Soc. 2014, 25, 1331-1337.

[34] Wei, A. A. J.; Joshi, A.; Chen, Y.; McIndoe, J. S. Experimental strategies for avoiding saturation effects in ESI-MS. ChemRxiv 2019, doi: 10.26434/ chemrxiv.8872487.v1.

[35] Paul, J.; Presset, M.; Le Gall, E.; Léonel, E.; Retailleau, P. Insights into the cobalt-catalyzed threecomponent coupling of mixed aromatic organozinc species, carbonyl compounds or imines and Michael acceptors: synthetic and mechanistic aspects. Synthesis 2018, 50, 254-266.

[36] Chen, C.; Zuo, H. P.; Chan, K. S. Catalytic hydrodebromination of aryl bromides by cobalt tetra-butyl porphyrin complexes with EtOH. Tetrahedron 2019, 75, 510-517. 